\title{
EDUCAÇÃO AMBIENTAL PARA ALÉM DO CAPITAL: UM DESAFIO DO SÉCULO XXI
}

Elza Neffa ${ }^{1}$

Elmo Rodrigues da Silva ${ }^{2}$

Krishna Neffa ${ }^{3}$

Resumo: A crise social, ambiental e econômica no mundo atual, agravada pela pandemia da COVID-19, aponta para os limites do modelo de desenvolvimento capitalista. No equacionamento de tal questão, a inclusão da teoria da complexidade no método científico e a Educação Ambiental para além do capital apresentam-se como potenciais ações transformadoras rumo a uma sociedade efetiva e substancialmente sustentável. Este artigo analisa a relação da ciência contemporânea com as transformações antrópicas na natureza, a fim de subsidiar a produção de múltiplos saberes para a Educação Ambiental no século XXI, exigindo mudanças profundas no curso do atual modelo de sociedade evitando-se, assim, o risco de extinção da vida planetária.

Palavras-chave: Educação Ambiental; Sustentabilidade Socioambiental; Processos Formativos.

Abstract: The social, environmental and economic crisis in the current world, aggravated by the COVID-19 pandemic, points to the limits of the capitalist development model. In addressing this issue, the inclusion of complexity theory in the scientific method and environmental education beyond capital are presented as potential transformative actions towards an effective and substantially sustainable society. This article analyzes the relationship between contemporary science and anthropic transformations in nature, in order to subsidize the production of multiple knowledge for environmental education in the 21st century, requiring profound changes in the course of the current model of society, thus avoiding the risk of extinction of planetary life.

Keywords: Environmental Education; Socio-Environmental Sustainability; Formative Processes. 


\section{Introdução}

A transição para um novo sistema reprodutivo para além do capital adquiriu uma atualidade histórica em razão da intensidade e da severidade da crise estrutural do sistema de reprodução sociometabólica do capital em curso e do seu agravamento pela pandemia da COVID-19. Se, em momentos pretéritos da história de ascendência do capital, as crises irrompiam turbulentas e eram seguidas por longas fases de expansão, a partir da década de 1970, conclui-se que o novo padrão se constitui de fases de recessão econômica frequentes, tendendo a um continuum em depressão (MÉSZÁROS, 2002).

Tomando por pressuposto que o sistema reprodutivo do capital é um modo de controle sociometabólico incontrolavelmente voltado para a expansão, inclusive com a produção e a multiplicação generalizada do desperdício, não se pode vislumbrar a criação de sociedades sustentáveis sem que haja a suspensão do imperativo auto-expansionista do capital, por meio da superação da própria ordem que causou a insustentabilidade socioambiental, expressa pela crise climática e, também, pela miséria física, emocional e mental, a qual os trabalhadores estão submetidos em seus processos de subjetivação em escala mundial e, também, sem que haja, um sistema adequado de planejamento, administrado sobre a base de uma sustentabilidade democrática - "entendida como o processo pelo qual as sociedades administram as condições materiais de sua reprodução, redefinindo os princípios éticos e sociopolíticos que orientam a distribuição de seus recursos ambientais" (ACSELRAD; LEROY, 2003, p. 9).

Este artigo analisa a relação da ciência contemporânea com as transformações antrópicas na natureza, a fim de subsidiar a produção de múltiplos saberes para a Educação Ambiental no século XXI, exigindo mudanças profundas no curso do atual modelo de sociedade evitando-se, assim, o risco de extinção da vida planetária. Para tal, realizou-se uma reflexão sobre a prática de Educação Ambiental orientada pela abordagem metodológica transdisciplinar, considerando-se que ela, além de possibilitar a integração da ecologia a outros ramos do saber, permite ainda a formulação de alternativas capazes de integrar uma nova economia à natureza e possibilita emergir uma maior autonomia do educando em seu processo existencial para agir-refletir-agir sobre o mundo.

Inicialmente é apresentada a construção do conhecimento técnicocientífico que possibilitou as inovações tecnológicas e as transformações das relações dos seres humanos com a natureza. Em seguida é mostrado o contexto do debate ambiental e dos impactos das ações humanas em que se inseriram essas inovações, destacando-se a necessidade de se construir novos instrumentos para o entendimento da realidade e de sua dinâmica, levando-se em conta que a construção do conhecimento é um processo dialógico permeado de contradições. E, por fim, são tecidas as considerações finais sobre novas humanidades possíveis para a construção de mundos ressignificados. 


\section{Inovações tecnológicas e transformações das relações dos seres humanos com a natureza}

A "aceleração da história", característica do final do século $X X$ e início do século XXI, é representação de uma época marcada por transformações em todos os níveis da vida planetária, com incertezas e laços frágeis configurandose em meio à compressão do espaço e do tempo. Desde o início do século XX, novos conhecimentos científicos relacionados à teoria quântica (Planck, em 1900), à teoria da relatividade (Einstein, em 1905), ao princípio da incerteza (Heisenberg, em 1927), à lei da complementaridade (Niels Bohr, em 1928), e mais recentemente, às estruturas dissipativas (llya Prigogine, em 1960) e ao pensamento complexo (MORIN, 2000; 2002; 2007), têm revelado a matéria como pulsante; os seres como conjuntos energéticos; as relações lineares como uma dentre várias dimensões da realidade; a vida, inclusive a humana, como teia de conexões; o macro e o microcosmos como campo de vibrações, fluxo de ondas, corrente de comunicações e dança de possibilidades.

O fundamento da ciência ocidental moderna construiu o mundo com ritmos diferenciados entre a tecnologia, mais acelerada, e a evolução mais lenta das crenças e do nosso olhar, o que nos incita a refletir sobre como mudar esse modelo mecanicista e capitalista de produção e consumo que ameaça a vida na Terra, a partir do questionamento sobre a compatibilidade entre crescimento econômico e sustentabilidade ambiental e sobre a possibilidade de se criar outras formas de existir que revele um sujeito com sensibilidade e responsabilidade ético-solidária na nova ordem planetária.

Esse contexto se explica, em parte, a partir da disseminação do método cartesiano que cindiu o ser humano da natureza, dessacralizando-a pela separação homem-sujeito, de um lado, e natureza-objeto, de outro, e "libertando definitivamente a ciência das concepções teológicas herdadas do mundo medieval' (SILVA; SCHRAMM, 1997, p. 357). O pensamento racionalista consolidou-se no século XVIII ao conjugar o método analítico, o determinismo, a causalidade e a linearidade com o conhecimento rigoroso da natureza, a partir de ideias matemáticas. Ao postular o mecanicismo, o mundomáquina passa a ser regulado por leis imutáveis e eternas. Com o universo explicado em função da organização e do movimento das partes, independente do observador humano, e o conhecimento científico assumido como modelo universalmente válido, desconsiderando os saberes que não coadunam com estes pressupostos, surgiram as promessas de paz e racionalidade, liberdade, igualdade e expansão do conhecimento gerador do progresso material que, no século XIX, impulsionaram a concepção do progresso social com a difusão do liberalismo, da instrução, da melhoria da segurança, do bem estar e da democracia como meio para alcançar a emancipação humana ${ }^{1}$.

\footnotetext{
${ }^{1}$ A categoria emancipação humana foi explicitada por Karl Marx, em 1843, no artigo publicado nos Anais Franco-Alemães sobre a questão judaica (MARX, 1963,1964). Adorno (2000) utiliza- 
O século $X X$ viu o padrão cultural eurocêntrico e norte-americano, pautado na lógica mercantil, ser globalizado como estilo de vida "superior" às outras culturas, o que intensificou a intervenção humana na natureza e fez brotar preocupações com os riscos ambientais, dentre outras razões, pelo fato do ser humano expandir o sistema técnico-científico e utilizá-lo para colocar a natureza a seu serviço. A ideia de progresso e de sua versão mais atual, o desenvolvimento, expressa a dominação dos seres humanos sobre a natureza e a origem do vocábulo latino volver (séc. XIII), donde provém desenvolvimento (séc. XX), revela a intenção de tirar a autonomia e o envolvimento de cada cultura e de cada povo com o seu espaço para incorporá-lo à lógica societária capitalista (PORTO-GONÇALVES, 2004).

O discurso ideológico que preconiza o potencial da ciência e da tecnologia contemporâneas como capazes de garantir o acesso dos povos ao desenvolvimento pressupõe compatibilidade entre sustentabilidade e capitalismo e constrói-se sobre o signo do crescimento econômico, do mercado globalizado, da prioridade da economia sobre a ecologia e da consolidação do neoliberalismo, sem atentar para o processo de humanização do ser humano.

Como decorrência, a humanidade chegou ao século XXI imersa em conflitos provenientes da pressão humana sobre os ecossistemas mundiais que se traduzem na mudança climática global; no efeito estufa; no buraco na camada de ozônio; no lixo tóxico; na bioacumulação de metais pesados e de agrotóxicos na cadeia alimentar; na produção e acumulação de resíduos sólidos; nos acidentes nucleares e em outros desastres ambientais; na alteração dos ciclos biogeoquímicos; na fome e na pobreza; na escassez de elementos naturais; além da contaminação do ar e da perda dos solos e da biodiversidade, sobretudo devido à destruição das florestas tropicais.

Esse conjunto de impactos cumulativos sobre a biosfera pode também explicar, em parte, o aumento de doenças epidêmicas provocadas por arbovírus, como a febre amarela, a dengue, a zika, o ebola, a gripe aviária e a mais recente pandemia (COVID-19) provocada pelo SARS-CoV 2, da família de coronavírus ${ }^{2}$, causando o óbito de centenas de milhares de pessoas em todo mundo, além dos impactos econômicos imprevisíveis e de longo prazo sobre as economias dos países. A esse respeito, Harvey (2020, p. 15) reforça essa análise quando afirma que:

a no sentido de um movimento de libertação consciente e de superação das formas de alienação material e simbólica, coletiva e individual.

2 Sete coronavírus humanos foram identificados ao todo pela ciência. O SARS-CoV-2 é o mais recente coronavírus responsável por causar a doença COVID-19. No Século XXI é a sexta vez que uma Emergência de Saúde Pública de Importância Internacional é declarada. As outras cinco foram: pandemia de gripe $\mathrm{H} 1 \mathrm{~N} 1$, em 2009; disseminação internacional de poliovírus em 2014; surto de ebola na África Ocidental, em 2014; vírus da zika e aumento de casos de microcefalia e outras malformações, em 2016; surto de ebola na República Democrática do Congo, em 2018 (OPAS \& OMS, 2020). 
há muito tempo eu tinha recusado a ideia de "natureza" como alheia e separada da cultura, economia e cotidiano. Eu tenho uma visão mais dialética e relacional da ligação metabólica com a natureza. O capital modifica as condições ambientais de sua própria reprodução, mas o faz num contexto de consequências não intencionais (como as mudanças climáticas) e contra as forças evolutivas autônomas e independentes que estão perpetuamente remodelando as condições ambientais. Deste ponto de vista, não existe um verdadeiro desastre natural. Os vírus mudam o tempo todo. Mas as circunstâncias nas quais uma mutação se torna uma ameaça à vida dependem das ações humanas.

Tais problemas socioambientais alimentam o debate na sociedade, há décadas, e apontam para a necessidade impreterível das ações humanas serem pautadas pelo Princípio da Precaução ${ }^{3}$, "uma das derivações éticas possíveis do princípio de incerteza de Heisenberg" (PORTO-GONÇALVES, 2004, p. 38), e por valores humanitários como solidariedade, generosidade, equidade, liberdade e democracia de alta intensidade.

A discussão sobre a sustentabilidade, trazida no bojo das análises sobre os riscos que a humanidade e o planeta enfrentam em função de um modelo de desenvolvimento que não considera os limites para a relação das sociedades com a natureza, requer a inclusão da dimensão cultural e política ao debate, na medida em que os efeitos da intervenção que o sistema técnico provoca sobre o meio ambiente não podem ser dissociados das relações sociais e do sistema de valores, ideologias, conhecimentos, intrínsecos a esse modelo civilizatório. A inserção das relações sociais no debate instiga uma análise sobre como, para que, para quem e em qual direção está sendo utilizado o conhecimento técnico-científico (ARENDT, 1983), tendo em vista que no estabelecimento das condições materiais de reprodução de sua existência, os seres humanos travam relações com a natureza e, nessa mediação, a tecnologia constitui-se um instrumental básico.

A reflexão sobre o uso que os interesses privados fazem do arsenal tecnológico para proliferação de bens de consumo supérfluos, descartáveis, ambientalmente nocivos e geradores de lucros nos remete ao interessante questionamento feito por Loureiro (2000) ao indagar: qual o direito que têm $20 \%$ dos habitantes mais ricos do planeta de se apropriarem de cerca de $80 \%$ da energia e de matérias primas produzidas anualmente, sendo os benefícios

\footnotetext{
3 O Princípio de Precaução é proposto "quando atividades podem conduzir a dano moralmente inaceitável, que seja cientificamente plausível, ainda que incerto, devem ser empreendidas ações para evitar ou diminuir aquele dano. Dano moralmente inaceitável refere-se a dano para os seres humanos ou para o ambiente, que seja uma ameaça à vida ou à saúde humanas, ou que seja sério e efetivamente irreversível, ou injusto com as gerações presentes e futuras, ou imposto sem a adequada consideração dos direitos humanos daqueles afetados [...]" (UNESCO, 2005, p. 14).
} 
dos avanços tecnológicos utilizados para melhorar a qualidade de suas vidas, em detrimento dos segmentos sociais excluídos do processo produtivo e destituídos das condições materiais que lhes permitam ter acesso a essa tecnologia?

O desafio ambiental colocado à humanidade na contemporaneidade consiste em articular os estilos de vida e os projetos socioambientais aos limites da capacidade de suporte 4 e de regeneração do meio ambiente ${ }^{5}$, incorporando a noção de "sustentabilidade democrática" (ACSERALD; LEROY, 2003, p. 28). Como construção social, fruto do embate entre vários atores em busca de hegemonia de suas posições, essa noção propõe uma mudança da concepção hegemônica de desenvolvimento, a qual privilegia a visão economicista, o mercado e o caráter infinito dos elementos naturais, para uma outra perspectiva de desenvolvimento que seja baseada em princípios de justiça social, superação das desigualdades socioeconômicas e construção democrática ancorada no dinamismo dos atores sociais. Nessa perspectiva, estudos sobre Ecologia Política ${ }^{6}$ apontam para a necessidade de se incorporar uma nova epistemologia que transcenda o campo da racionalidade científica e da objetividade do conhecimento e ilumine a emergência de estratégias educativas alternativas e de novas relações de trabalho, de modo a democratizar o mercado e submeter os agentes econômicos às prioridades do desenvolvimento do ser humano, em todos os níveis e dimensões.

O estabelecimento dessas relações depende de outras significações sociais, de novas formas de subjetividade, de diferentes posturas no processo de produção da existência, além de outras práticas entre ciências, técnicas e indústrias que, submetidas a um controle ético-político, apresentem a possibilidade de uma religação dos saberes para entender os fenômenos complexos. Portanto, uma nova maneira de pensar e de produzir conhecimento, trazida pela reflexão transdisciplinar ${ }^{7}$, pode contribuir para a

\footnotetext{
${ }^{4}$ Para um sistema ambiental ou ecossistema, a capacidade de suporte é entendida como o nível de utilização dos recursos ambientais que ele pode suportar, garantindo-se a sustentabilidade e a conservação de tais recursos e o respeito aos padrões de qualidade ambiental.

5 Em ecologia de ecossistemas, a regeneração do meio ambiente está associada ao termo resiliência, que indica a capacidade dos ecossistemas em absorver perturbações sem alterar significativamente suas características de estrutura e funcionalidade.

${ }^{6}$ Essa visão, que desloca a discussão da sustentabilidade do campo econômico para o campo das relações sociais tendo como princípio norteador a eqüidade, insere-se na corrente do ambientalismo denominada justiça ambiental ou "ecologismo dos pobres", campo de estudo da Ecologia Política (ALIER, 2007; ALIMONDA, 2003, 2006; LIPIETZ, 2002).

7 O ponto de vista transdisciplinar permite que a realidade seja considerada como multidimensional e multirreferencial na medida em que é estruturada por múltiplos níveis, tanto de realidade quanto de percepção. Essa nova ótica de visualizar o mundo prevê que a passagem de um nível de realidade para outro é assegurada pela lógica do terceiro incluído, que leva em conta a contradição e a inclusão do terceiro termo de uma proposição, e que a estrutura da totalidade dos níveis de realidade ou percepção é complexa, tendo em vista que cada nível é o que é porque todos os níveis existem ao mesmo tempo. Ao postular a
} 
instauração de uma mentalidade que recuse: os especialismos; o fosso existente entre as ciências e, entre elas e o conhecimento filosófico, artístico e da experiência vivida no cotidiano da humanidade; a lógica linear e o raciocínio dicotômico que preconiza o certo em contraposição ao errado, o bem ao mal, a ordem à desordem; a redução utilitária da racionalidade que se submete à tecnologia, à idolatria ao mercado, ao espírito do lucro e à competitividade, acarretando perda das solidariedades; a cisão entre inteligência e sensibilidade e entre subjetividade e objetividade; a devastação ambiental; a manipulação das imagens $\mathrm{e}$ isolamento das pessoas conectadas às mídias eletrônicas e desconectadas do mundo real. Em suma, a humanidade necessita urgentemente de novas abordagens metodológicas e uma nova práxis para compreender e transformar a realidade socioeconômica para além do capital. Nesse sentido, a questão ambiental assume um protagonismo evidente no debate atual, por representar as condições materiais da vida planetária.

\section{O contexto do debate ambiental e dos impactos das ações humanas}

A questão ambiental deve ser compreendida através das relações e das interpretações que se estabeleceram historicamente entre os processos artificial/cultural e o natural. Sem pretensão de dar conta de todos os fatores que marcaram a trajetória dos movimentos sociais e políticos que ampliaram a consciência humana para tal questão, a seguir serão apresentados alguns momentos que alimentaram, e ainda alimentam, esse debate.

Nos tempos atuais, em que se aponta um possível colapso ambiental em nível planetário, em função da degradação do meio ambiente, um dos temas polêmicos a esse respeito está relacionado ao crescimento populacional, como defendido por correntes neomalthusianas. Erlich e Erlich (1986), por exemplo, argumentam que a "bomba populacional", relativa ao crescimento exponencial da população mundial, associa-se ao desenvolvimento da tecnociência, a partir da Revolução Industrial. Em conjunto com outros fatores, esse crescimento seria considerado um dos mais relevantes para o impacto ambiental sobre a biosfera, uma vez que a população mundial teria atingido a marca de um bilhão de habitantes no início do século XIX e, posteriormente, saltaria para dois bilhões em 130 anos, três bilhões em 30 anos, quatro bilhões em 15 anos e cinco bilhões em 12 anos $^{8}$ (BURSZTYN; PERSEGONA, 2008, p. 14).

complexidade como um dos pilares da Transdisciplinaridade, junto com os níveis de realidade e a lógica do terceiro incluído, Basarab Nicolescu (1999) destaca-a como uma teoria que permite ao cientista conceber a realidade dos fenômenos em diversas dimensões, na qual os problemas se manifestam polidisciplinares, transversais, multidimensionais, transnacionais, globais e planetários, na perspectiva de compreender a mutação em processo no mundo.

8 Segundo o relatório da ONU (2017), a população mundial era de 7,6 bilhões de pessoas, devendo chegar a 8,6 bilhões em 2030. Para 2050, a projeção é de 9,3 bilhões e, em 2100, mais de 11,2 bilhões. A cada ano, a população mundial aumenta em 80 milhões de pessoas. Os jovens com menos de 25 anos representam $43 \%$ de todos os habitantes do planeta. 
Nos anos 1960, o tema ambiental trazido pelos movimentos pacifistas, bem como por alguns cientistas e políticos, marcou uma geração e suscitou questionamentos sobre os rumos do planeta em razão do confronto que parecia evidenciar-se entre o modo de reprodução sociometabólica do capital e a natureza. Desde então, "a revolução do meio ambiente" (MILANI, 1998, p. 312) foi levada para a esfera política e a questão ambiental tomou impulso após o lançamento do relatório do Clube de Roma (Relatório Meadows, "Limites do Crescimento", de 1972), que apontou cenários futuros catastróficos para a humanidade se nada fosse feito. Para Milani (1998, p. 306):

Os anos 1970 foram marcados pela aceleração, em diferentes âmbitos (político, econômico, ecológico, cultural e científico). [...]. Tal evolução conduziu, de fato, à internacionalização e à transnacionalização do problema ambiental [...]. O meio ambiente conduziu dirigentes locais e líderes mundiais a institucionalizar o problema do desenvolvimento sustentável, mobilizando e organizando as representações coletivas nas quais desempenham papel central a mídia, os atores sociais, os operadores econômicos, o mundo da ciência, a opinião pública, bem como o setor político [...].

Entretanto, ainda segundo esse autor, o meio ambiente passou a ser mais um componente do processo de globalização ${ }^{9}$, com relações de interdependência ecológica e econômica podendo se conformar em regulações solidárias (ou negociadas) entre os atores, por meio de legislações ou regulações realizadas pelo mercado econômico, a exemplo do princípio poluidor-pagador ${ }^{10}$ ou de créditos de carbono $^{11}$ negociados entre setores econômicos.

9 "A globalização econômica [...] é o resultado de uma política, implementada por governos nacionais e instituições internacionais, mediante instrumentos muito específicos, tais como abertura dos mercados de capitais, bens e serviços, a desregulamentação do mercado de trabalho e a eliminação de qualquer obstáculo legal ou burocrático à 'livre empresa' e, sobretudo, aos investidores internacionais. A globalização neoliberal visa, portanto, a criar as condições de dominação das grandes corporações e fundos de investimento que confrontam as empresas nacionais numa concorrência muito desigual em mercados abertos" (CASTRO, 2020, p.1).

${ }^{10}$ A Declaração do Rio sobre Meio Ambiente e Desenvolvimento, de 1992, em seu Princípio nº 16 diz que "as autoridades nacionais devem procurar assegurar a internalização dos custos ambientais e o uso de instrumentos econômicos, levando em conta o critério de quem contamina" [...] (ANTUNES, 2006. p. 31).

11 Protocolo de Quioto determina que os países desenvolvidos signatários reduzam suas emissões de gases de efeito estufa em 5,2\%, em média, relativas ao ano de 1990, entre 2008 e 2012, primeiro período de compromisso. Parte da redução das emissões de carbono poderia ser feita através de instrumentos de negociações, como o Mecanismo de Desenvolvimento Limpo (MDL). O crédito de carbono do MDL é denominado Redução Certificada de Emissão (RCE) - ou em inglês, Certified Emission Reductions (CER) (MMA, 2020). 
Os anos que precederam a Conferência das Nações Unidas sobre o Meio Ambiente Humano, em Estocolmo (1972), foram marcados por desastres ambientais que mobilizaram a opinião pública internacional. A partir daí, os acidentes ocorreram com maior frequência e em dimensões ampliadas, evidenciando a gravidade do problema e alimentando os debates nas posteriores conferências mundiais e acordos internacionais voltados para a área ambiental. Alguns desastres/eventos estão apresentados no Quadro $1^{12}$.

Quadro 1: Cronologia dos desastres ambientais e dos principais eventos internacionais sobre o meio ambiente.

\begin{tabular}{|c|c|}
\hline Ano & Breve relato de alguns acidentes \\
\hline $\begin{array}{l}1942- \\
1950\end{array}$ & $\begin{array}{l}\text { Estados Unidos: a empresa Hooker Chemical Plastics depositou } 20 \text { mil ton. de } \\
\text { resíduos industriais no leito do Love canal, em 1958. Houve afloramento de } \\
\text { resíduos organoclorados nos playgrounds das escolas e, em 1970, nas } \\
\text { residências. }\end{array}$ \\
\hline 1945 & $\begin{array}{l}\text { Japão: o lançamento de bombas atômicas sobre Hiroshima e Nagasaki pelos } \\
\text { EUA provocou } 210 \text { mil mortes. Ainda hoje há } 350 \text { mil pessoas com a "carta de } \\
\text { irradiado", afetados por câncer, anemia ou esterilidade. }\end{array}$ \\
\hline 1952 & $\begin{array}{l}\text { Inglaterra: o Big Smoke, nevoeiro de poluição atmosférica que encobriu Londres, } \\
\text { foi causado pela queima de combustíveis fósseis na indústria e nos transportes e } \\
\text { acarretou a morte de } 12.000 \text { londrinos deixando outros } 100.000 \text { doentes. }\end{array}$ \\
\hline 1957 & $\begin{array}{l}\text { União Soviética: a explosão em tanque de resíduos nucleares do "Desastre de } \\
\text { Kyshtym" contaminou a região de Mayak e matou } 200 \text { pessoas de câncer. }\end{array}$ \\
\hline 1956 & $\begin{array}{l}\text { Japão: a Corporação Chisso lançou fertilizantes químicos contendo mercúrio na } \\
\text { Baía de Minamata e gerou o "Mal de Minamata", provocando milhares de óbitos. }\end{array}$ \\
\hline $\begin{array}{l}1962- \\
1970\end{array}$ & $\begin{array}{l}\text { Guerra do Vietnã: o despejo de mais de } 70 \text { milhões de litros de Dioxina nas } \\
\text { florestas por aviões americanos levou à destruição de } 1,5 \text { milhões de hectares de } \\
\text { floresta; ao nascimento de crianças deformadas; e } 40 \text { mil soldados americanos e } \\
\text { ex-combatentes foram contaminados e morreram acometidos pelo câncer. }\end{array}$ \\
\hline 1966 & $\begin{array}{l}\text { Brasil: a Fábrica Rhodia S/A em Cubatão (SP) despejou resíduos industriais na } \\
\text { Baixada Santista deixando: dezenas de mortos; } 40 \text { mil contaminados; } 2 \text { milhões } \\
\text { de } \mathrm{m}^{2} \text { de solo e água poluídos por } 300 \text { mil toneladasde lixo químico poluente. }\end{array}$ \\
\hline 1967 & $\begin{array}{l}\text { Inglaterra: o acidente com o petroleiro Torrey Canyon, próximo da costa inglesa, } \\
\text { com } 119 \text { mil } \mathrm{m}^{3} \text { lançados ao mar, causou a poluição das regióes marinhas, } \\
\text { costeiras e oceânicas, danos à vida marinha e prejuízos à pesca e ao turismo. }\end{array}$ \\
\hline 1972 & $\begin{array}{l}\text { Suécia: lançou o primeiro alarme mundial em relação à chuva ácida com a morte } \\
\text { de peixes devido ao aumento da acidez de lagos e rios, afetando árvores em } \\
\text { outros países. }\end{array}$ \\
\hline 1972 & $\begin{array}{l}\text { Suécia (Estocolmo): realização da Conferência das Nações Unidas sobre o Meio } \\
\text { Ambiente Humano e do Programa das Nações Unidas para o Meio Ambiente - } \\
\text { PNUMA pela Assembleia Geral da ONU, em dezembro de } 1972 \text {. }\end{array}$ \\
\hline 1976 & $\begin{array}{l}\text { Itália (Seveso): Fábrica de tricolorafenol. Explosão no reator com emissão de } \\
\text { nuvem de dioxina. Mais de } 2 \text { mil mulheres tiveram permissão para abortar; } 193 \\
\text { feridos; milhões de toneladas de terra removidas; mais de } 3000 \text { animais mortos. }\end{array}$ \\
\hline
\end{tabular}

Continua...

12 Os dados para elaboração desses cenários tiveram como fontes: Bursztyn \& Persegona (2008); Programa do Meio Ambiente da Organização das Nações Unidas (UNEP, 2009); Barbosa (2010); Costa et al. (2012); Araújo (2015); EBC (2015); Greenpeace Brasil (2015); Instituto Ethos (2020); World Health Organization (2020), ONU Brasil (2020). 


\begin{tabular}{|c|c|}
\hline Ano & Breve relato de alguns acidentes \\
\hline 1979 & $\begin{array}{l}\text { Estados Unidos: acidente na Central Nuclear Three Mile Island causado por } \\
\text { falha do equipamento devido o mau estado do sistema técnico e erro operacional. } \\
\text { Foi o primeiro grande vazamento em usina nuclear. }\end{array}$ \\
\hline 1984 & $\begin{array}{l}\text { Brasil (Cubatão - SP): o rompimento de duto de gasolina da Petrobras na favela } \\
\text { de Socó provocou incêndio, matando } 90 \text { pessoas, além do vazamento de } 700 \text { mil } \\
\text { litros de combustível no meio ambiente. }\end{array}$ \\
\hline 1984 & $\begin{array}{l}\text { Índia (Bhopal): o vazamento de gases tóxicos da fábrica de pesticidas Union } \\
\text { Carbide lançou } 40 \text { toneladas de Isocianeto de Metila na atmosfera. Provocou: } \\
\text { morte de mais de } 8 \text { mil pessoas; } 200 \text { mil feridos; milhares de indivíduos com } \\
\text { doenças permanentes, abortos e nascimentos com deformidade. Entre } 1978 \text { e } \\
1984 \text { ocorreram mais de } 6 \text { acidentes nessas instalações. }\end{array}$ \\
\hline 1986 & $\begin{array}{l}\text { URSS (Ucrânia). O vazamento na Usina Nuclear de Chernobyl afetou a Ucrânia, } \\
\text { Finlândia, Escandinávia, Polônia, Alemanha e França. Foram } 31 \text { mortos, } 135 \text { mil } \\
\text { pessoas removidas e } 600 \text { mil atingidas pela radiação. Inutilização de } 140 \text { mil km² } \\
\text { de área. Entre } 15 \text { e } 30 \text { mil óbitos posteriores por razões associadas ao acidente. }\end{array}$ \\
\hline 1987 & $\begin{array}{l}\text { Brasil (Goiânia - GO): o acidente radioativo com uma cápsula contendo Cloreto } \\
\text { de Césio retirada de um aparelho de radioterapia abandonado contaminou } 243 \\
\text { pessoas, muitas delas crianças que pintaram o corpo com o pó fluorescente. }\end{array}$ \\
\hline 1988 & $\begin{array}{l}\text { ONU: criação do Painel Intergovernamental para as Mudanças Climáticas (IPCC), } \\
\text { um dos principais instrumentos internacionais para o monitoramento climático. }\end{array}$ \\
\hline 1989 & $\begin{array}{l}\text { Alasca: o petroleiro Exxon V } \\
\text { vazamento de } 50 \text { milhões de } \\
\text { ficaram comprometidos. Mort }\end{array}$ \\
\hline 1991 & $\begin{array}{l}\text { Kuwait: destruição de poços } \\
\text { Pérsico. Mais de um milhão } \\
\text { óleo queimado causando mor }\end{array}$ \\
\hline 1992 & $\begin{array}{l}\text { Meio Ambiente e } \\
\text { o na Agenda } 21 .\end{array}$ \\
\hline 1995 & $\begin{array}{l}\text { Reino Unido: doença da "vaca louca" (encefalopatia bovina espongiforme) em } \\
\text { 1986, devido à reciclagem de carne, ossos, sangue e vísceras usados na } \\
\text { fabricação de ração animal. Dizimação de rebanhos na Europa. A doença atingiu } \\
\text { além da Europa, o Canadá e os EUA. }\end{array}$ \\
\hline 2000 & $\begin{array}{l}\text { ou o derramamento de } 1.292 \text { milhões de litros de } \\
\text { oara (RJ). Vazamento de } 7.250 \text { litros no litoral de São } \\
\text { e óleo cru vazados pela refinaria em Araucária (PR). }\end{array}$ \\
\hline 2002 & $\begin{array}{l}\text { Espanha: maior catástrofe ambiental na costa da Galícia. Derramamento de } 77 \\
\text { mil toneladas de óleo no mar pelo Petroleiro Prestige. }\end{array}$ \\
\hline 2002 & $\begin{array}{l}\text { la Mundial sobre Desenvolvimento Sustentável }(\text { Rio }+10) \text { para } \\
\text { quistas surgidas desde a Cúpula da Terra de } 1992 \text { e para } \\
\text { rromissos da Agenda } 21 \text { em ações concretas e tangíveis. }\end{array}$ \\
\hline 2003 & $\begin{array}{l}\text { Brasil: o rompimento da barragem de rejeitos Indústria Cataguazes (MG) lançou } \\
1,2 \text { bilhões de litros de substâncias no rio Pomba, atingindo o rio Paraíba do Sul. } \\
\text { Destruição do ecossistema; mortandade de animais; escassez de água. }\end{array}$ \\
\hline 2005 & $\begin{array}{l}\text { China: explosões na usina petroquímica da cidade de Jilin. Vazamento de } \\
\text { benzeno e nitrobenzeno no rio Songhua. Mancha de } 80 \mathrm{~km} \text { atravessou a cidade } \\
\text { de Harbin com mais de } 9 \text { milhões de habitantes. }\end{array}$ \\
\hline 200 & $\begin{array}{l}\text { Brasil: a Amazônia sofreu uma das mais intensas secas da história recente, com } \\
\text { o menor índice pluviométrico observado em } 40 \text { anos }\end{array}$ \\
\hline 2 & $\begin{array}{l}\text { Brasil: o rompimento de barragem em Miraí/MG provocou o vazamento de mais } \\
\text { de dois milhões de metros cúbicos de água e argila. A empresa foi multada em } \mathrm{R} \$ \\
75 \text { milhões, mas os danos ainda permanecem evidentes. }\end{array}$ \\
\hline
\end{tabular}




\begin{tabular}{|c|c|}
\hline Ano & Breve relato de alguns acidentes \\
\hline 2010 & $\begin{array}{l}\text { México: a explosão da plataforma de petróleo da British Petroleum, no Golfo do } \\
\text { México, despejou cinco milhões de barris, matou } 11 \text { pessoas, feriu } 17 \text { e destruiu } \\
\text { habitats, vida marinha e prejudicou as populações locais. }\end{array}$ \\
\hline 2011 & $\begin{array}{l}\text { Brasil: o vazamento de óleo na Bacia de Campos/RJ pela empresa americana } \\
\text { Chevron lançou no mar cerca de três mil barris de petróleo, provocando uma } \\
\text { mancha de } 160 \text { quilômetros de extensão e animais mortos. }\end{array}$ \\
\hline 2011 & $\begin{array}{l}\text { Brasil (Região Serrana - RJ): a chuva intensa por uma semana provocou } \\
\text { deslizamentos de encostas e inundações, deixando } 918 \text { mortos e cerca de } 30 \text { mil } \\
\text { pessoas desabrigadas. }\end{array}$ \\
\hline 2015 & $\begin{array}{l}\text { Brasil (Mariana - MG): o rompimento da barragem de Fundão, da empresa } \\
\text { Samarco, provocou uma onda de lama tóxica de mais de dez metros de altura. } 60 \\
\text { milhões de metros submergiram milhares de pessoas e cidades, além de } \\
\text { comprometer seriamente o meio ambiente. }\end{array}$ \\
\hline 2015 & $\begin{array}{l}\text { Brasil (Rio+20): Uma das maiores conferências da ONU com } 188 \text { países } \\
\text { signatários das proposições de: desenvolvimento da economia verde; de criação } \\
\text { de um novo organismo para tomada de decisões globais; de fortalecimento do } \\
\text { PNUMA e dos Objetivos do Desenvolvimento Sustentável (ODS). }\end{array}$ \\
\hline 2018 & $\begin{array}{l}\text { Brasil: Incêndio no Museu Nacional (RJ), danificando mais de } 20 \text { milhões de } \\
\text { material do maior acervo de antropologia e história natural do Brasil. }\end{array}$ \\
\hline 2019 & $\begin{array}{l}\text { Brasil (Brumadinho - MG): o rompimento da barragem de contenção de rejeitos } \\
\text { de minério de ferro da empresa Vale S.A provocou severos impactos } \\
\text { socioambientais com } 249 \text { mortes e } 21 \text { pessoas desaparecidas. }\end{array}$ \\
\hline 2019 & $\begin{array}{l}\text { Brasil: o derramamento de petróleo cru em mais de } 2.000 \mathrm{~km} \text { do litoral do } \\
\text { Nordeste e Sudeste contaminou praias, recifes, corais e mangues, com impactos } \\
\text { sobre a biodiversidade marinha, o turismo, a economia local e a população. }\end{array}$ \\
\hline 2019 & $\begin{array}{l}\text { Mundo: concentração recorde dos níveis de dióxido de carbono, metano e óxido } \\
\text { nitroso, principais gases do efeito estufa, acelerando os efeitos das mudanças } \\
\text { climáticas, com consequências na escassez hídrica e aumento do nível do mar. }\end{array}$ \\
\hline 2 & $\begin{array}{l}\text { Mundo: Pandemia COVID-19 (SARS-CoV2). Total de } 2.198 .061 .550 \text { pessoas } \\
\text { contaminadas e } 440.290 \text { mortes, conforme dados de } 17 \text { jun. } 2020 \text { (WHO, 2020). }\end{array}$ \\
\hline
\end{tabular}

O último evento (a Pandemia da COVID-19), elencado no quadro acima, torna ainda mais aguda todas as crises acumuladas, sejam elas de natureza socioeconômica e humanitária, sanitária, política e ambiental, que se interconectam em graus e proporções globais imprevisíveis. As reflexões sobre as atitudes coletivas diante da morte e das incertezas sobre o futuro trazidas pelo Coronavírus, em seus diferentes graus de nocividade, indicam cenários sombrios vividos pela humanidade que precisam ser combatidos. No atual momento histórico, somos impelidos a avançar e acelerar as ações, destacando a importância do papel do conhecimento científico, da mobilização das forças sociais solidárias e, sobretudo, do Estado Democrático para a transição para um modo de produção que vá para além do capital.

$\mathrm{Na}$ pretensão de se consolidar os caminhos na superação dos problemas apresentados, espera-se que o conhecimento avance dentro de uma perspectiva inter/transdisciplinar, e que ela seja cada vez mais incorporada pelos cientistas e tomadores de decisões. Portanto, a Educação Ambiental, em seu viés crítico, conforme sugerem Layrargues (2000); Leff (2001) e Loureiro (2004), entre outros, é uma ferramenta potente para a práxis 
social transformadora, tão necessária como urgente, para se enfrentar os desafios postos aos indivíduos, à sociedade civil, às empresas e aos governos para manter as condições que possibilitem a continuidade da vida terrestre.

\section{Ferramentas para entender a realidade em sua dinâmica, processo e contradições}

O esforço para construirmos, com a utilização de elementos materiais e simbólicos, uma nova ordem mundial, a partir da desordem forjada pelas crises históricas intrínsecas ao sociometabolismo reprodutivo vigente, torna-se um imperativo quando fracassam as múltiplas "soluções" para os problemas socioeconômicos (desnutrição, desemprego, subemprego, ausência ou deficiência de saneamento básico, doenças evitáveis como sarampo, tuberculose etc.) e socioambientais (escassez hídrica, desertificação, inundações, extinção de espécies vegetais e animais, pandemia de COVID-19 etc.) que recaem sobre a humanidade e o planeta. As soluções propostas e implementadas têm se mostrado, muitas vezes, ineficientes em razão de se deixarem restringir pela ordem existente, não sendo capazes de definir uma alternativa que ajude as pessoas a encontrar as ferramentas para compreender a realidade em sua totalidade dinâmica e devolver-lhes os poderes de decisão que Ihes foram alienados.

A incorporação de novas sensibilidades, metodologias, ferramentas práticas e teóricas de saberes científicos e não científicos torna-se necessária posto que a autonomia, a sensibilidade, a cooperação, a integração, a solidariedade, o afeto, a empatia, a criatividade e a responsabilidade ética constituem fundamentos para a construção de um sistema de produção contrahegemônico que necessita emergir e tornar-se hegemônico o quanto antes.

A dificuldade para lidarmos com a complexidade do mundo contemporâneo e, em especial, com as transformações do capitalismo, levanos a refletir sobre a estrutura de pensamento forjada pela revolução científica e a postular que, além de uma ecologia integrada aos outros ramos do saber, é preciso integrar uma nova economia à natureza. Isto porque a era do economicismo transformou 0 processo civilizatório em uma questão eminentemente econômica, independente da totalidade social, encarando a necessidade como demanda de compradores com dinheiro e excluindo as necessidades de uma multidão despossuída do equivalente de troca universal. O confronto dos ideais de uma determinada política econômica com a questão ética pressupõe saber, no caso dos países da periferia do sistema capitalista como o Brasil, qual é a utilidade da adoção de políticas que articulam somente o crescimento econômico em detrimento do desenvolvimento humano e da sustentabilidade socioeconômica e ambiental de sua população?

A partir das críticas às distorções da vida humana, à apropriação utilitária dos elementos naturais e à violência contra os seres viventes, os cientistas do século XXI estão sendo chamados a produzir conhecimentos e 
tecnologias que compatibilizem o crescimento econômico com a sustentabilidade socioambiental. $\mathrm{E}$, diante da complexidade do problemático jogo de relação de forças do tabuleiro geopolítico global, que envolve diferentes atores sociais portadores de visões de mundo e interesses diversificados, convocam-se sujeitos transdisciplinares capazes de: compreender a multidimensionalidade da realidade; interligar diversos conhecimentos científicos e esses com os saberes tradicionais; incluir lógicas contraditórias; possibilitar a construção e a implementação de estratégias que favoreçam os princípios do equilíbrio ambiental e da justiça social, com base em uma ética pautada na relação de responsabilidade com a natureza; e de solidariedade entre os seres humanos que estejam comprometidos, fundamentalmente, com a proposição de outro modo de produção para além do capital.

O Quadro 2, organizado por Simão Filho (2003, p. 95), a partir das contribuições de vários estudiosos, proporciona a visualização de algumas dimensões da sustentabilidade e de critérios a elas correlacionados.

Quadro 2: Dimensões e Critérios da Sustentabilidade

\begin{tabular}{|c|c|}
\hline DIMENSÕES & CRITÉRIOS \\
\hline Social & $\begin{array}{l}\text { Alcance de razoável patamar de homogeneidade social; } \\
\text { Distribuição justa de renda e de emprego pleno e/ou autônomo com qualidade de vida decente; } \\
\text { Igualdade de gênero com incorporação da mulher na cidadania econômica, política e social; } \\
\text { Universalização de cobertura das políticas de educação, saúde, habitação e seguridade social. }\end{array}$ \\
\hline Cultural & $\begin{array}{l}\text { Mudanças no interior da comunidade (equilíbrio entre respeito à tradição e à inovação); } \\
\text { Capacidade de autonomia para elaboração de um projeto nacional integrado e endógeno; } \\
\text { Autoconfiança com abertura para o mundo; } \\
\text { Preservação de valores e práticas de identidade; promoção dos direitos das minorias. }\end{array}$ \\
\hline Ecológica & $\begin{array}{l}\text { Preservação do capital/natureza na sua produção de recursos renováveis; } \\
\text { Limitação do uso dos recursos não-renováveis. }\end{array}$ \\
\hline Ambiental & Respeito e realce da capacidade de autodepuração dos ecossistemas naturais. \\
\hline Territorial & $\begin{array}{l}\text { Balanceamento entre configurações rurais e urbanas, com melhoria desses ambientes; } \\
\text { Superação das disparidades inter-regionais; } \\
\text { Implementação de estratégias de desenvolvimento ambientalmente seguras para áreas } \\
\text { ecologicamente frágeis. }\end{array}$ \\
\hline Econômica & $\begin{array}{l}\text { Desenvolvimento econômico intersetorial equilibrado; } \\
\text { Segurança alimentar; } \\
\text { Capacidade de modernização contínua dos instrumentos de produção; } \\
\text { Razoável nível de autonomia na pesquisa científica e tecnológica; } \\
\text { Inserção soberana na economia internacional. }\end{array}$ \\
\hline $\begin{array}{l}\text { Político- } \\
\text { institucional } \\
\text { (Nacional) }\end{array}$ & $\begin{array}{l}\text { Democracia definida em termos de apropriação universal dos direitos humanos; } \\
\text { Desenvolvimento da capacidade do Estado para implementar o projeto nacional, em parceria } \\
\text { com empreendedores; } \\
\text { Democratização da sociedade e do Estado, com estabelecimento de coesão social; } \\
\text { Aplicação efetiva do princípio de precaução; } \\
\text { Proteção da diversidade biológica e cultural. }\end{array}$ \\
\hline $\begin{array}{c}\text { Política } \\
\text { Internacional }\end{array}$ & $\begin{array}{l}\text { Eficácia do sistema de prevenção de guerras da ONU e promoção da cooperação internacional; } \\
\text { Um pacote Norte-Sul de co-desenvolvimento baseado na igualdade; } \\
\text { Controle Internacional efetivo do sistema internacional financeiro e de negócios; } \\
\text { Controle Internacional do Princípio da Precaução na gestão do meio ambiente; prevenção das } \\
\text { mudanças globais negativas; proteção da diversidade biológica e cultural e gestão do } \\
\text { patrimônio global como herança comum da humanidade; } \\
\text { Sistema de cooperação científica e tecnológica internacional e eliminação parcial do caráter de } \\
\text { commodity da ciência e tecnologia, assumindo-se como propriedade da herança comum da } \\
\text { humanidade. }\end{array}$ \\
\hline
\end{tabular}

Fonte: Simão Filho apud Quintas (2004, p. 123-124). 
As transformações que vêm ocorrendo na contemporaneidade impulsionam posturas, visões de mundo e comportamentos inovadores e habilitam o ser humano a lidar com os medos transportadores de paralisias e inércias que o mantém preso à "roda da ansiedade e da angústia", males aguçados pela Pandemia da COVID-19 no século XXI.

A autoconstrução do novo ser humano requer uma transição paradigmática para torná-lo cooperativo, solidário e capaz de desempenhar um papel fundamental na emancipação do trabalho humano e na construção de uma socioeconomia informada pelo altruísmo, pela cooperação, pela reciprocidade, pela solidariedade e pela amorosidade (ARRUDA, 2003).

Em outras palavras, forjar o ser humano solidário pela educação da práxis é um processo de sensibilização que advém da assunção de cada ser humano, individual e coletivamente, responsabilizar-se pela atualização consciente das potencialidades que o capacitarão a transcender a sua atual etapa evolutiva. A matriz da aprendizagem da práxis incorpora práticas ecossociais, laborais e políticas, e práticas de desenvolvimento pessoal.

Na perspectiva de Casanova (2006, p. 249), "a necessidade das novas ciências e das novas dialéticas se converterá na tarefa pedagógica mais importante para a sobrevivência do projeto humanista e da humanidade". Assim, a educação surge como capacidade transformadora para a sustentabilidade da vida e emancipação dos seres humanos, postulando a formação de grupos sociais localizados geopoliticamente para que se organizem e participem dos processos decisórios relativos à problemática socioambiental que os afeta diretamente. Para tanto, a convivência com lógicas contraditórias que se interdefinem e se complementam, a tolerância com diferentes percepções humanas, a criação de espaços coletivos para uma atuação política consciente dos sujeitos, o exercício da participação na construção da cidadania e a adoção da ética de solidariedade são algumas das estratégias que permitem a compreensão do mundo em sua complexidade, da vida em sua totalidade, e o rompimento com os padrões civilizatórios que reforçam as formas de domínio e de usurpação inerentes ao capitalismo em detrimento ao desenvolvimento humano e ao cuidado com o planeta.

A Educação Ambiental para a sustentabilidade da vida serve a um projeto socioambiental que contribui para a transformação da relação do ser humano com a natureza que, vinculada às relações sociais e às dinâmicas socioambientais, permite a superação da sociedade de classes, das relações de dominação e da exclusão social, dentre outros aspectos que demandam capacidade crítico-reflexiva e práxis consciente voltada para o futuro. Por relacionar-se à questão da perpetuação da espécie humana no planeta, essa educação aponta para transformações que vão desde as atitudes cotidianas até os modelos de gestão dos macroespaços, requerendo uma percepção da complexidade das dimensões socioculturais, políticas, econômicas e ambientais em interação, que constituem a sociedade da qual emergem 
saberes e práticas, na qual o ser humano emerge como criador de si mesmo e do mundo, em um devenir que constrói a sua humanização.

\section{A construção de conhecimento enquanto processo dialógico}

Questões explicitadas por jovens aprendizes, como por exemplo, "para que serve o que estou estudando e como ligar os estudos à minha vida?" demonstram a necessidade de uma educação que ressalte o trabalho de problematização e o ensino para a compreensão da totalidade. Amit Goswami (2008) confirma essa necessidade ao salientar que o atual sistema educacional se baseia na resolução de problemas desconectados da realidade.

Diversamente do paradigma cientificista moderno que nos legou a ideia da existência de um único nível de realidade, a teoria da relatividade e a revolução quântica, ao introduzirem novos conceitos no campo científico como o quantum, a indeterminação, a aleatoriedade, a descontinuidade, a incerteza, a complementaridade e não-separabilidade parte/todo, colocaram em xeque o dogma filosófico contemporâneo da existência de um só nível de realidade. Ao propor a noção de causalidade global, que pressupõe a existência de correlações não locais em detrimento do conceito-chave da física clássica da causalidade local, a mecânica quântica abriu uma porta para a percepção da existência de outros níveis de realidade além daquele que percebemos no mundo macrofísico. A partir daí, a ciência possibilitou outras interpretações paradigmáticas, como o sentido da unidade das coisas, a experiência estética e o reencantamento da natureza, e instaurou uma relação dialógica entre sujeitos criativos que intercomunicam lógicas complementares, concorrentes e antagônicas, para construir uma nova ciência, que junta o que está fragmentado e disperso nas especializações, com vistas a compreender os sentidos dos contextos complexos sincronizados por uma razão aberta às dimensões imaginárias, míticas e poéticas.

Diante de uma realidade que se transforma em velocidade instantânea, superar as limitações intrínsecas ao cartesianismo, ao reducionismo, ao racionalismo, requer mudanças dos modelos educacionais que, por mais sofisticados que sejam, foram construídos por paradigmas do passado para uma realidade que não existe mais. Atualizar as estruturas de pensamento para tornar os seres humanos aptos a construírem novos modelos interpretativos da realidade demanda análise das teorias que surgiram do estudo dos chamados sistemas complexos. Esses sistemas, compostos por grande número de partes interdependentes e inter-relacionadas, apresentam o comportamento do todo transcendendo o comportamento das partes tomadas isoladamente. Nesses sistemas, os elos entre causas e efeitos desaparecem ou, dito de outra forma, pequenas causas podem resultar em grandes efeitos.

A realidade do mundo global unificado pela internet vem aumentando o grau de interdependência entre as partes e, cada vez mais, operações realizadas na China, por exemplo, têm reflexos no ocidente, tornando 
fundamental a compreensão da imprevisibilidade do futuro de um mundo cuja dinâmica já demanda, na contemporaneidade, planejamento por fluxos e não por ciclos. Tal imprevisibilidade advém da inexistência da estabilidade em sistemas complexos que, por estarem expostos a desordens externas, ruídos e acasos, são capazes de evoluir no diálogo com essas desordens e no seu uso para aperfeiçoar o padrão de ordem interna, que se desordena e reordena sem cessar, o que Ihes possibilita permanentes reorganizações sendo, por isso, chamados de processos auto-organizativos, adaptativos e autopoiéticos. Mas, para que essa auto-organização ocorra como processo natural e espontâneo é necessário que haja conectividade entre as partes.

A complexidade dos sistemas vivos supõe a auto-organização pelo ruído. É a partir da decodificação pelo ruído que se desestrutura a fixação do padrão cognitivo e se ampliam os modelos de referência internos ao sistema. No processo ensino-aprendizagem, o ruído pode ser entendido como contravenção, como elemento desordenador da interpretação, como desordem criativa e, nos processos científicos, como teorias concorrentes, hipóteses complementares, que não se enquadram no sistema de explicação já solidificado. É por isso que os processos de aprendizagem "não dirigidos" podem provocar o aparecimento de novos padrões de leitura do mundo.

Forjar relações pedagógicas a partir de uma nova arquitetura que possibilite o fluxo de informações, de saberes e de práticas capazes de realizar as necessárias transformações políticas, sociais, econômicas e culturais prementes na contemporaneidade dominada pelo egoísmo, pelo lucro e pela competição inerentes à lógica desumanizadora do capital, demanda a criação de possíveis inspirados em ideias, questionamentos e fazeres erguidos sobre os alicerces de uma nova escola. Essa nova escola não está dada, mas necessita ser criada com a utilização de um novo pensar-fazer que integre novos componentes epistemológicos advindos das novas ciências da complexidade e da tecnociência - a cibernética, a epistemologia genética, a computação, os sistemas auto-regulados, adaptativos e autopoiéticos, as ciências da organização, do caos determinista, dos atratores e dos fractais.

A construção de uma prática educativa comprometida com a autonomia do educando, em seu processo existencial para agir-refletir-agir sobre o mundo, e com o entendimento da organização e do possível como conceitoschave para compreensão dos alcances e dos limites das ciências da complexidade, necessita abrir-se ao cotidiano do educando, tendo como cerne a afirmação dos valores fundamentais do campo da ética pessoal, dentre eles, a honestidade, a lealdade, a confiança e o respeito mútuo. O papel do professor transdisciplinar, no contexto da Educação Ambiental, é o de estimular continuamente a construção de redes integradoras de fundamentos teóricos e conteúdos programáticos significativos que rompam com a lógica verticalizadora de uma educação bancária, puramente informativa, de modo a aproximar as reflexões críticas às práticas criativas que incitem a participação, a cooperação, a solidariedade, a tolerância, a alteridade e o compromisso 
político com a transformação social, assumindo o risco da inovação, da criação do novo, pois como ensinou Krishnamurti (1992), não é sinal de saúde estar bem adaptado a uma sociedade doente.

\section{Tecendo breves considerações finais sobre novas humanidades para construção de mundos ressignificados}

A análise das transformações que as inovações tecnológicas acarretam nas relações dos seres humanos com a natureza destaca-se no debate ambiental para que a formação dos seres humanos no século XXI seja contextualizada e as práticas socioambientais sejam articuladas à base estrutural da sociedade, ou seja, ao modo como os seres humanos se organizam para a produção de suas existências, tanto material como espiritual.

O povo brasileiro, inserido no atual panorama mundial de injustiça social e de degradação ambiental, em sua busca inseparável de autonomia individual e emancipação social, requer uma práxis política consciente dos trabalhadores conjugada com uma formação sustentada em um saber ambiental que acolha a alteridade, valorize a diferença, respeite a diversidade e redesenhe as bases de um projeto social alternativo capaz de ressignificar os sentidos da vida rumo a uma sociedade pautada por novos padrões civilizatórios, cujo cerne seja "o reforço à consciência das verdades humanas que fazem a qualidade da vida: amor, amizade, comunhão e solidariedade" (MORIN, 2020). Afinal, como dizia Marx (2007, p. 29), "a libertação é um ato histórico, não um ato mental".

\section{Agradecimentos}

À Universidade do Estado do Rio de Janeiro e à Fundação de Amparo à Pesquisa do Estado do Rio de Janeiro (FAPERJ) pelo apoio à realização de projetos desenvolvidos pelos autores.

\section{Referências}

ACSERALD, H.; LEROY, J. P. Novas premissas da sustentabilidade democrática. Projeto Brasil Sustentável e Democrático. Rio de Janeiro: Fase, Série Cadernos de Debate, n. 1, 2. ed., 2003.

ADORNO, T. L. W. Educação e emancipação. São Paulo. Paz e Terra, 2000.

ALIER, J. M. $\mathrm{O}$ ecologismo dos pobres: conflitos ambientais e linguagens de valoração. São Paulo: Contexto, 2007.

ALIMONDA, H. Introducción: Política, Utopía, Naturaleza. In: ALIMONDA, H. Ecología Política. Naturaleza, sociedad y utopía. Buenos Aires: CLACSO, Consejo Latinoamericano de Ciencias Sociales, p.1-7, 2003. 
ALIMONDA, H. Una nueva herencia em Comala: apuntes sobre la ecología política latinoamericana y La tradición marxista. In: ALIMONDA, Héctor. Los tormentos de La materia. Aportes para una ecología política latinoamericana. São Paulo: Ambiente \& Sociedade, Ano IV, n. 9, p. 93-112. $2^{\circ}$ Semestre de 2001.

ANTUNES, P. B. Direito ambiental. Rio de Janeiro: Lúmen Júris. Buenos Aires: CLACSO, Consejo Latinoamericano de Ciencias Sociales, 2006.

ARAÚJO, H. Tsunami de lama tóxica: o maior desastre ambiental do Brasil. Jornal El País, Brasil. Publicado em: 31 Dez. 2015. Disponível em: $<$ https://brasil.elpais.com/brasil/2015/12/30/politica/1451479172 309602.html>. Acesso em: 3 jun. 2020.

ARENDT, H. A condição humana. Rio de Janeiro: Forense, 1983.

ARRUDA, M. Humanizar o infra-humano: a formação do ser humano integral: homo evolutivo, práxis e economia solidária. Petrópolis/RJ: Vozes, 2003.

ARRUDA, M. Tornar real o possível: a formação do ser humano integral, economia solidária, desenvolvimento e o futuro do trabalho. Petrópolis/RJ: Vozes, 2006.

BARBOSA, V. Os 10 maiores acidentes petrolíferos da história. São Paulo. Revista Exame, São Paulo. Publicado em 10 out. 2010. Disponível em $<$ https://exame.com/mundo/10-maiores-acidentes-petroliferos-historia556774/>. Acesso em: 1 mai. 2020.

BOHR, N. Física atômica e conhecimento humano: ensaios 1932-1957/Niels Bohr; tradução Vera Ribeiro. Rio de Janeiro: Contraponto, 1995.

BURSZTYN, M.; PERSEGONA, M. A grande transformação ambiental: uma cronologia da dialética do homem-natureza. Rio de Janeiro: Garamond, 2008.

CASTRO, R. P. Globalização. Dicionário da educação profissional em saúde. Rio de Janeiro: Fiocruz, 2020. [Online]. Disponível em: $<$ http://www.sites.epsjv.fiocruz.br/dicionario/verbetes/glo.html\#: :text=Ram\%C3 \%B3n\%20Pe\%C3\%B1a\%20Castro,\%E2\%80\%9D\%20(Hobsbawn\%2C\%20199 5)>. Acesso em: 19 jun. 2020.

CHÂTELET, F. Uma história da razão: Entrevistas com Emile Noël. Rio de Janeiro: Zahar, 1994.

COSTA, D. T. et al. Grandes Impactos Ambientais no Mundo. Caderno Meio Ambiente e Sustentabilidade. Curitiba, v.1, n.1, 2012.

COSTA, W. M. Bases epistemológicas da questão ambiental: determinações, mediações e contradições. Seminário Universidade e Meio Ambiente: Documentos Básicos. Anais... Brasília: IBAMA, p. 99-105, 1989. 
CUNHA, S. B. da. GUERRA, A. J. T. (orgs.). A questão ambiental: diferentes abordagens. Rio de Janeiro: Bertrand Brasil, 2007.

DESCARTES, R. Discours de la Méthode. Paris: Garnier-Flammarion, 1966.

DIAMOND, J. Colapso: como as sociedades escolhem o fracasso ou 0 sucesso. São Paulo: Record, 2005.

EMPRESA BRASIL DE COMUNICAÇÃO (EBC). Desastres ambientais no Brasil. 2015. [Online]. Disponível em:<http://www.ebc.com.br/noticias/meioambiente/2015/11/conheca-os-principais-desastres-ambientais-ocorridos-nobrasil>. Acesso em: 1 jun. 2020.

EHRLICH, P. R.; EHRLICH, A. H. The Population Bomb. Rev. ed. New York: Random House, 1986.

FREITAS, C. M. et al. Desastres naturais e saúde: uma análise da situação do Brasil. Ciência e Saúde Coletiva (Impresso), Fiocruz, v.19, n.9, p. 3645-3656, 2014..

GOSWAMI, A. Criatividade quântica: despertar o nosso potencial criativo. São Paulo: Aleph, 2008.

GREENPEACE BRASIL. Desastre no Golfo do México completa cinco anos. 2015. Disponível em: <https://www.greenpeace.org/brasil/blog/desastreno-golfo-do-mexico-completa-cinco-anos/>. Acesso em: 10 mai. 2020.

HARVEY, D. Política anticapitalista em tempos de COVID-19. In: DAVIS, Mike, et al: Coronavírus e a luta de classes. Terra sem Amos: Brasil, p.13-24, 2020.

INSTITUTO ETHOS. Retrospectiva de 2019 e perspectivas para 2020 na área ambiental. São Paulo, 2020. Disponível em: $<$ https://www.ethos.org.br/cedoc/retrospectiva-de-2019-e-perspectivas-para2020-na-area-ambiental/>. Acesso em: 18 Jun. 2020.

KRISHNAMURTI, J. Comentários sobre o viver. São Paulo: Cultrix, 1992.

LAYRARGUES, P. P. Educação para a gestão ambiental: a cidadania no enfrentamento político dos conflitos socioambientais. In: LOUREIRO, C. F. B., LAYRARGUES, P. P., CASTRO, R. S. de (orgs.). Sociedade e meio ambiente: a Educação Ambiental em debate. São Paulo: Cortez, p. 1-34, 2000.

LEFF, E. Saber ambiental: sustentabilidade, racionalidade, complexidade, poder. Petrópolis, Rio de Janeiro: Vozes, 2001.

LIPIETZ, A. A ecologia política, solução para a crise da instância política? In: ALIMONDA, H. (org.). Ecología Política. Naturaleza, sociedad y utopía. Buenos Aires: CLACSO, Consejo Latinoamericano de Ciencias Sociales, p.815, 2002.

LOUREIRO, C. F. B. Teoria social e questão ambiental: pressupostos para uma práxis crítica em Educação Ambiental. In: LOUREIRO, C. F. B., 
LAYRARGUES, P. P., CASTRO, R. S. de (orgs.). Sociedade e meio ambiente: a Educação Ambiental em debate. São Paulo: Cortez, p.13-51, 2000.

LOUREIRO, C. F. B.. Trajetórias e fundamentos da Educação Ambiental. São Paulo: Cortez, 2004.

MARX, KI. Manuscritos econômico-filosóficos. Lisboa: Edições 70, 1963/64.

MARX, K.; ENGELS, F. A ideologia alemã. São Paulo: Boitempo, 2007.

MÉSZÁROS, I. Para além do capital. São Paulo: Boitempo, 2002.

MILANI, C. O Meio Ambiente e a Regulação da Ordem Mundial. Contexto Internacional. Rio de Janeiro: Puc Rio, v. 20, n. 2, jul/dez. 1998, p. 303-347.

MINISTÉRIO DO MEIO AMBIENTE (MMA). Protocolo de Quioto. Disponível em: <https://www.mma.gov.br/clima/convencao-das-nacoes-unidas/protocolode-quioto.html>. Acesso em: 25 mai. 2020.

MORIN, E. Entrevista. França: Jornal CNRS, 09 abril 2020.

MORIN, E. Os sete saberes necessários à educação do futuro. São Paulo: Cortez; Brasília, DF: UNESCO, 2002.

MORIN, E.; CIURANA, E. R.; MOTTA, R. D. Educar na era planetária: o pensamento complexo como método de aprendizagem pelo erro e incerteza humana. São Paulo: Cortez; Brasília, DF: Unesco, 2007.

MORIN, E.; LE MOIGNE, J. L. A inteligência da complexidade. São Paulo: Peirópolis, 2000.

NICOLESCU, B. O manifesto da transdisciplinaridade. São Paulo: Trion, 1999.

ORGANIZAÇÃO DAS NAÇÕES UNIDAS (ONU). População mundial atingiu 7,6 bilhões de habitantes. ONU News. Publicado em 21 Jun. 2017. Disponível em: $<$ https://news.un.org/pt/story/2017/06/1589091-populacao-mundial-atingiu-76bilhoes-de-habitantes>. Acesso em: 21 abr. 2020.

ORGANIZAÇÃO DAS NAÇÕES UNIDAS (ONU BRASIL). Brasil está entre os 10 países com maior número de afetados por desastres nos últimos 20 anos. Publicado em: 24 nov. 2015. Disponível em: $<$ https://nacoesunidas.org/onu-brasil-esta-entre-os-10-paises-com-maior-

numero-de-afetados-por-desastres-nos-ultimos-20-anos/>. Acesso em: 18 mai. 2020.

ORGANIZAÇÃO DAS NAÇÕES UNIDAS (ONU BRASIL). A ONU e o Meio Ambiente. Disponível em: <https://nacoesunidas.org/acao/meio-ambiente/>. Acesso em: 25 mai. 2020. 
ORGANIZAÇÃO PANAMERICANA DE SAÚDE (OPAS); ORGANIZAÇÃO MUNDIAL DE SAÚDE (OMS). Folha informativa: COVID-19 (doença causada pelo novo coronavírus). Atualizada em: 17 jun. 2020. Disponível em: $<$ https://www.paho.org/bra/index.php?option=com content\&view=article\&id=61 01:covid19\&ltemid=875>. Acesso em:18 jun. 2020.

PORTO-GONÇALVES, C. V. O desafio ambiental. Rio de Janeiro, Distribuidora Record de Serviços de Imprensa S/A, 2004.

QUINTAS, J. S. Educação no processo de gestão ambiental: uma proposta de Educação Ambiental transformadora e emancipatória. In: LAYRARGUES, P. P. (coord.). Identidades da Educação Ambiental brasileira. Ministério do Meio Ambiente. Diretoria de Educação Ambiental. Brasília: Ministério do Meio Ambiente, p. 86-113, 2004.

RATIER, R. Quais foram os maiores desastres ecológicos no mundo? Revista Super Interessante. Atualizado em 4 jun. 2018. Disponível em:<https://mundoestranho.abril.com.br/ambiente/quais-foram-os-maioresdesastres-ecologicos-do-mundo/>. Acesso em: 3 jun. 2020.

ROSSET, C. A Anti-Natureza: elementos para uma Filosofia Trágica. Rio de Janeiro: Espaço e Tempo, 1989.

SANTOS, B. de S. Para um novo senso comum: a ciência, o direito e a política na transição paradigmática. São Paulo: Cortez, 2000. A crítica da razão indolente: contra o desperdício da experiência.

SILVA, E. R. da; SCHRAMM, R. F. A questão ecológica: entre a ciência e a ideologia/utopia de uma época. Cadernos de Saúde Pública. Rio de Janeiro, v.13, n.3. p. 355-382, jul-set, 1997.

SILVA, E. R. 212 f. O curso da água na história: simbologia, moralidade e a gestão de recursos hídricos. Tese (Doutorado em Saúde Pública). Rio de Janeiro: Escola Nacional de Saúde Pública. Fundação Oswaldo Cruz, 1998.

SIMÃO FILHO, M. Crise e Sustentabilidade no uso dos Recursos Pesqueiros. Brasília: Ibama, 2003.

UNITED NATIONS EDUCATIONAL, SCIENTIFIC AND CULTURAL ORGANIZATION (UNESCO). The precautionary principle. Paris: Unesco, 2005. Disponível em: <https://unesdoc.unesco.org/ark:/48223/pf0000139578>. Acesso em: 5 mai. 2020.

WORLD HEALTH ORGANIZATION (WHO). Coronavirus disease (COVID19). Situation Report - 149. Disponível em: <https://www.who.int/docs/defaultsource/coronaviruse/situation-reports/20200617-COVID-19-sitrep-

149.pdf?sfvrsn=3b3137b0 8>.Acesso em: 18 mai 2020. 